\title{
5 billeder fra Jemen af Tom Christoffersen
}

En subjektivt arabistisk læsning

af forskningsbibliotekar Stig T. Rasmussen

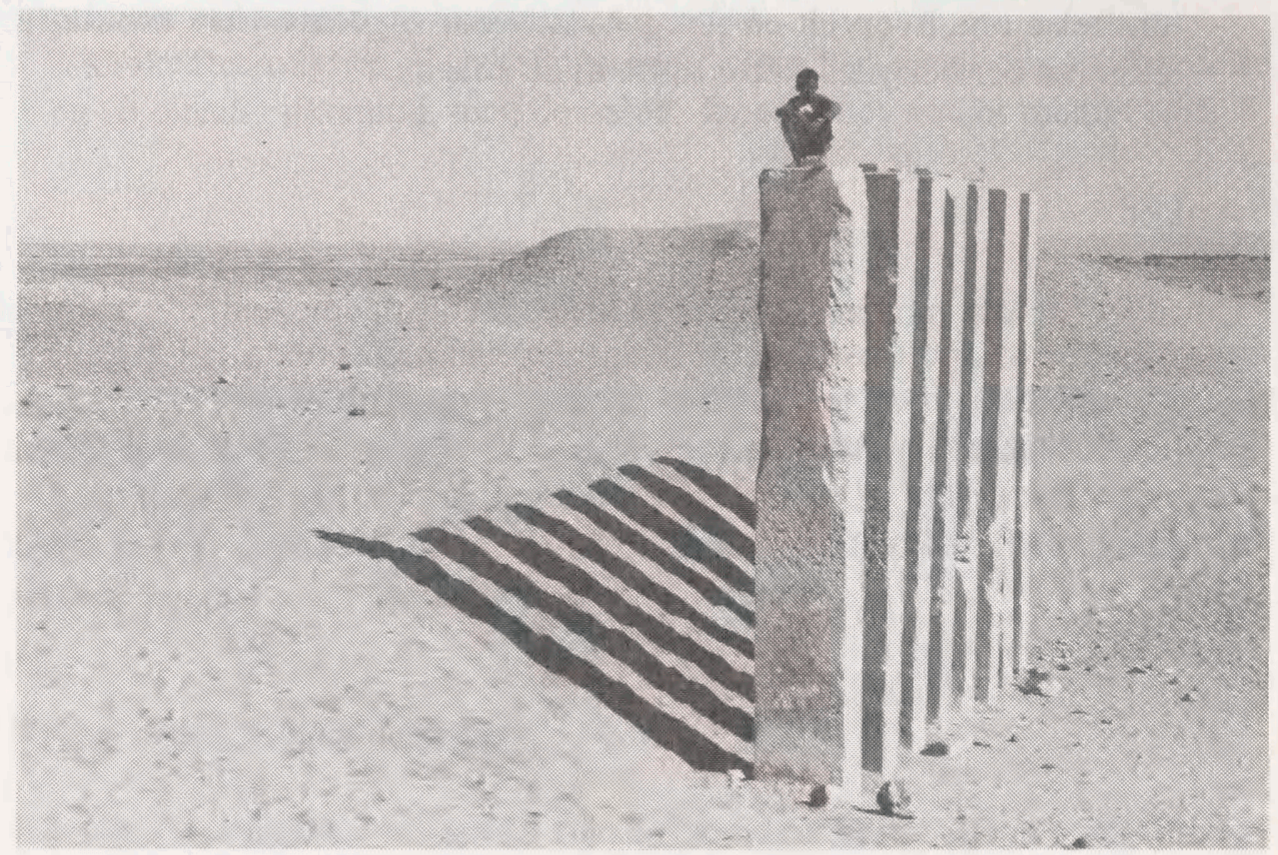

Billede $n r .1$ viser en dreng, der med front mod betragteren sidder på toppen af én ud af syv firkantede stensøjler i et ørkenlandskab, belyst af den lavtstående sol, der falder skråt ind fra højre, således at de syv søjler kaster kraftige diagonale skygger op mod øverste venstre hjørne.

Drengen er mørkt klædt, og skikkelsen fremtræder sort i kontrast mod himlens og baggrundens grå nuancer og i korrespondens med de syv skygger på sandet. På drengens bryst sidder et stykke hvidt stof, måske en stump tørklæde, af en uregelmæssig form, der korresponderer med formen på de spredte sten i $\varnothing$ rkenen - lyse til højre foran søjlerne, mørke i mellemgrunden til venstre.

Drengens arme danner en rhombe, hvis form går igen i såvel søjlerne som deres skygger set som hhv. en lys og en mørk, stribet flade. Arabisten vil associere til den sammenklappelige læsepult, der set fra siden er $\mathrm{x}$-formet og hvorpå især religiøse skrifter anbringes - og til visdommens syv søjler. 


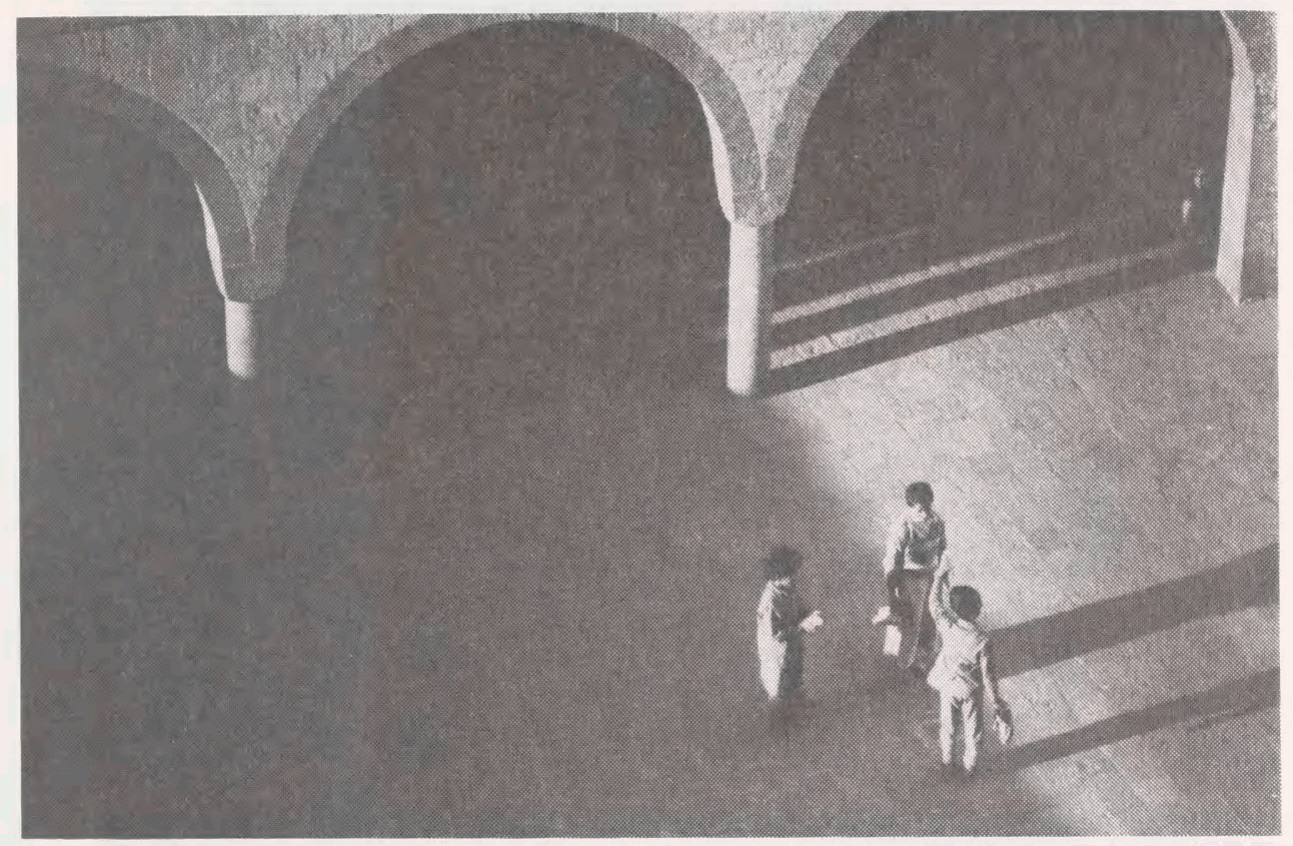

På billede $n r .2$ står tre drenge i en diskuterende gruppe i en gård, der ses skråt oppefra, så gruppen befinder sig i billedets nederste højre hjørne. I billedets baggrund løber tre buer fra venstre over to søjler mod højre til en murpille, bag hvis fod en fjerde dreng sidder på hug. De tre drenge har deres fodtøj i hånden: det er en religiøs skole eller en moské, vi ser ned i.

Sceneriet er belyst af en lav sol fra venstre, så de tre drenge og søjlerne kaster lange skygger vinkelret på gårdens firkantede sten. Den midterste drengs pullover er vandret stribet i lyst og mørkt, parallelt med skyggerne (hvorved der en passant bemærket - kunne være antydet syv søjler...).

Et af de lyse mellemrum mellem søjlernes skygger kaster som en projektør lyset på den fjerde drengs ansigt, der er vendt ud mod gruppen - og mod beskueren. 


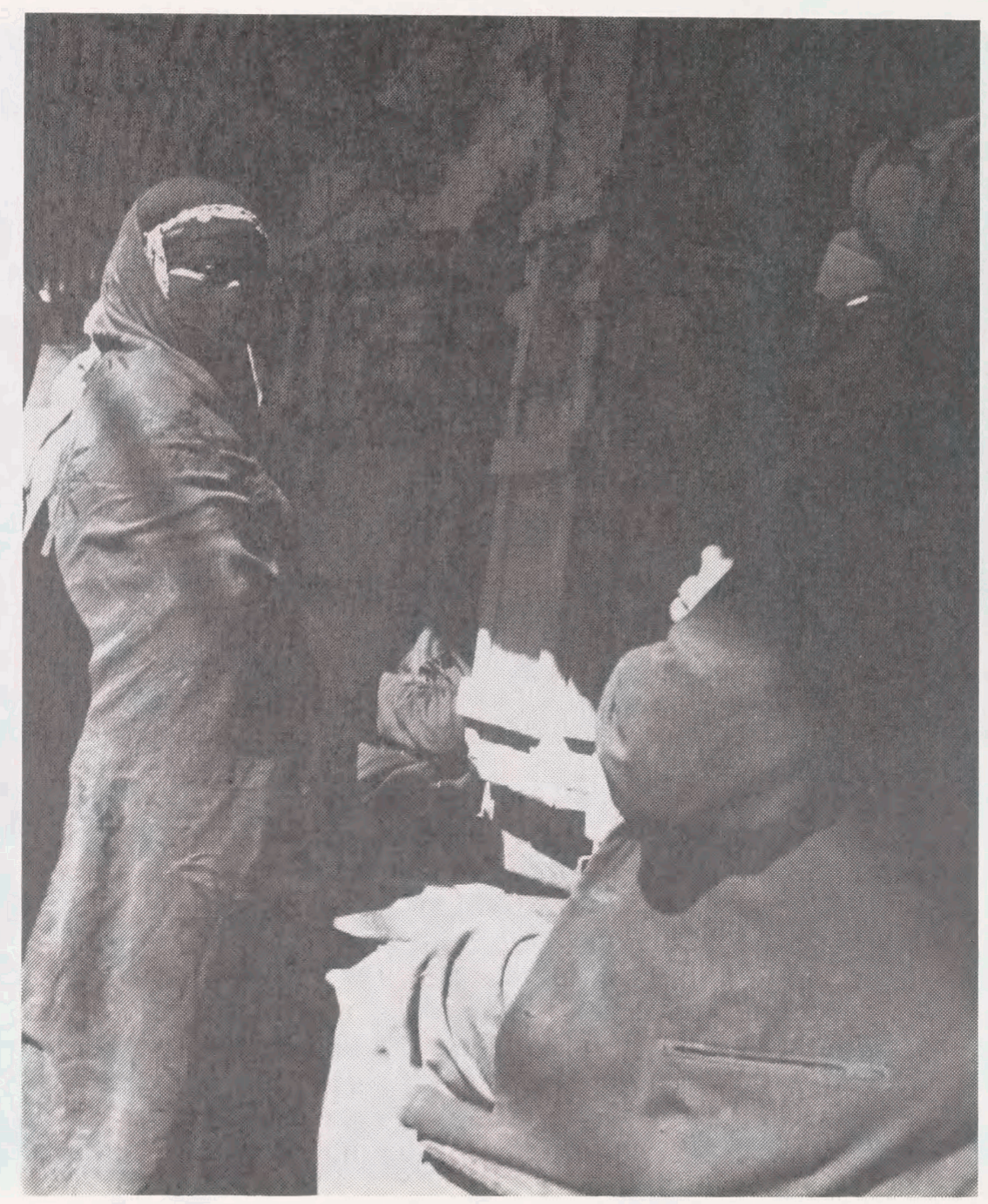

I billede $n r .3$ konfronteres en mand og en kvinde i en bazargade. Han sidder ned i højre side af billedet med siden til betragteren og ansigtet vendt mod kvinden, der står op i billedets venstre side lidt længere væk.

Han bærer vestlig jakke, turban og mørke solbriller over mundens let misbilligende trækning og holder armene over kors. Hun er helt indhyllet i traditionelle gevandter. Hendes hovedklæde og ansigtsslør lader kun øjnene fri - hun ser roligt, næsten fast på os over den tynde, sorte gaze, der ligger upåkrævet stramt over næsen og de fyldige læber (- slørets erotik er ikke mindre meddelsom end stone-washed jeans).

Mellem manden og kvinden ses solidt tømmerværk i en forretnings skodder, påklæbet billeder af Jemens regent i jakkesæt og i uniform: ingen kvinder hér! (men bag kvindens hoved, øverst i venstre hjørne tælles syv, nej måske otte søjlelignende riller i et bølgebliktag). 


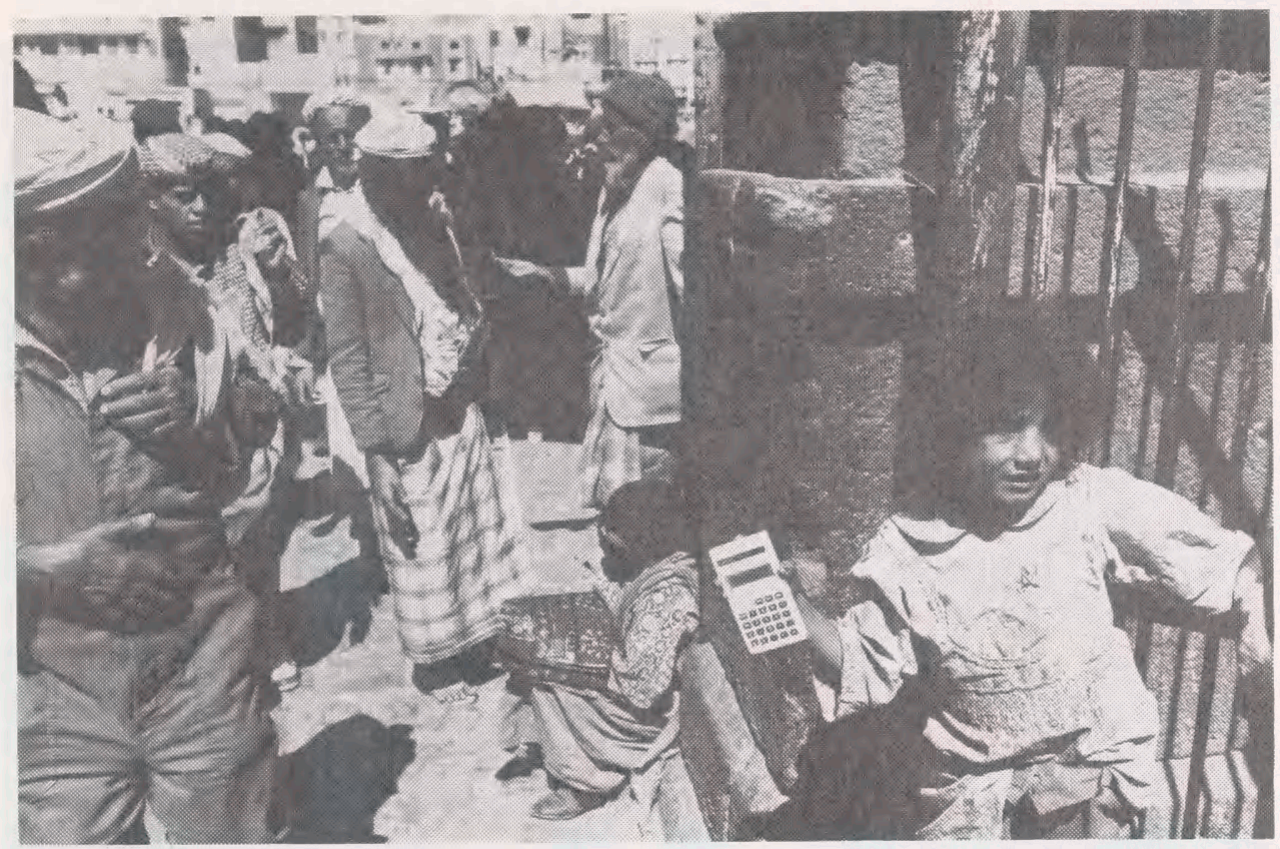

Hovedpersonen i billede $n r .4$ er en 6-7 års pige. Hun står foran en gitterport $\mathrm{i}$ billedets højre forgrund, bag hende ses en solid kvaderstensmur, der fylder højre tredjedel af billedet. De to tredjedele til venstre udfyldes af ældre og yngre jakke- og kjortelklædte mænd med forskelligt hovedtøj i forgrunden og karakteristisk jemenitiske huse i baggrunden.

Et par af mændene bærer bylter, et par diskuterer eller handler - scenen er et marked.

I mellemgrunden, op ad stenmuren, sidder et andet barn og sælger mønstret stof. Mellem sig selv og det andet barn holder pigen i forgrunden en lommeregner.

Lommeregneren er glat og hvid og står klart mod murens ru, grå sten; plastictastaturets geometri spænder mod det runde mønster og broderierne på pigens lyse kjole, men korresponderer med den midterste mands ternede kjortel: linjerne løber parallelt $\mathrm{i}$ de to vidt forskellige kulturgenstande. Lommeregnerens firkantede form korresponderer også med det siddende barns stof, medens stoffets blomstrede mønster er langt mere i familie med pigens kjole: et kontrapunktisk fremadløb fra baggrundens kvadrerede huse til pigen, der ser forbi os ud af billedet (gitteret og dets skyggers antal på muren tør man knap nok tælle...). 


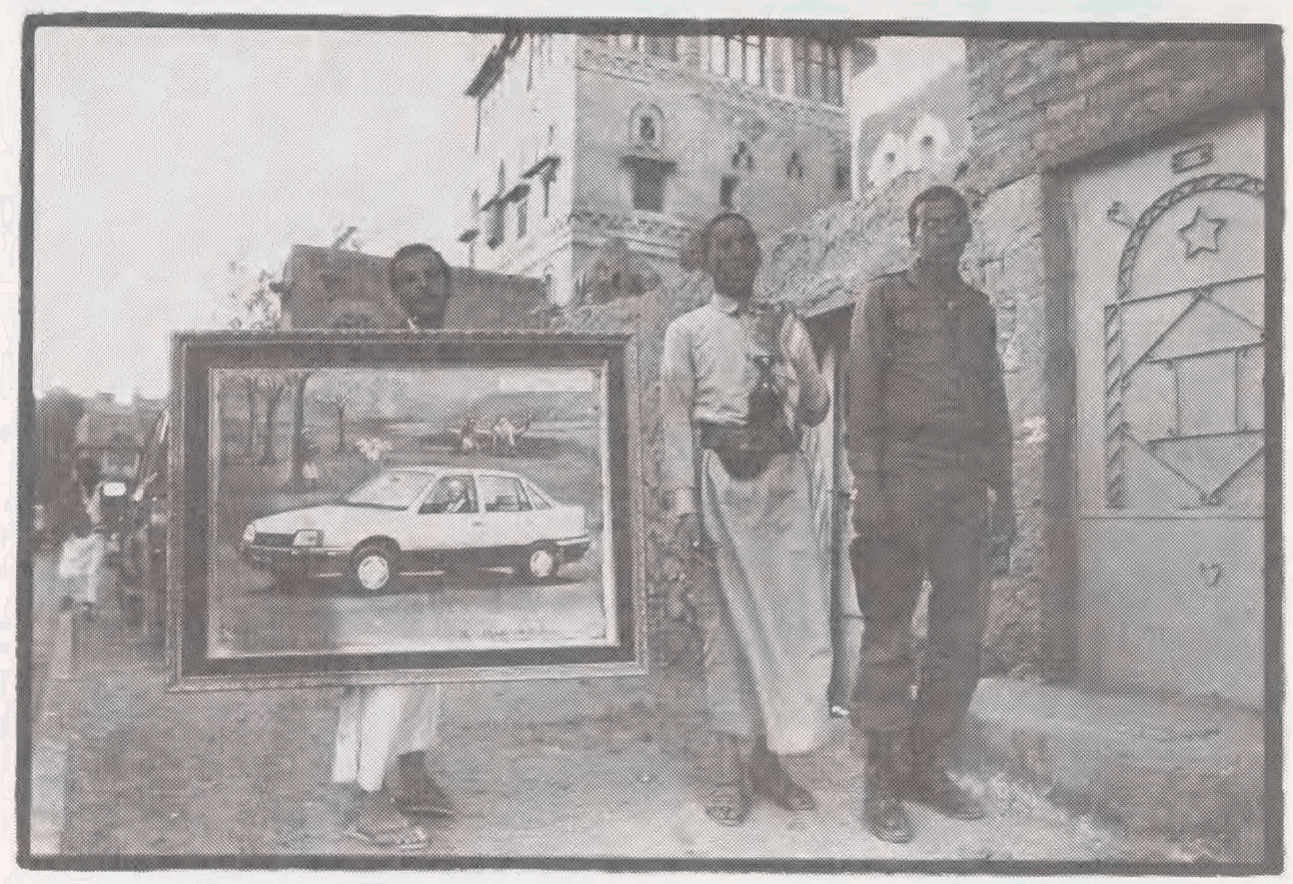

Billede $n r .5$ viser tre mænd i en gade i Sanaa, Nordjemen; til højre løber en groft pudset murstensmur fra en geometrisk mønstret jernport ned mod mellemgrunden, der går ind i væggen til et firkantet tårn med luger, glughuller og vinduer, samt geometriske mønstre i en frise under rækkerne af disse åbninger. Bag muren ses det Øverste af et énetages hus, med to buede vinduer; såvel viduesrammerne som husets hjørner og tagskæg er malet hvide.

Manden længst til højre er i uniform. Manden i midten er iklædt den lange, arabiske kjortel med bredt, zigzagmønstret bælte, hvori den typisk jemenitiske dolk er stukket ned midtfor, og han har et mønstret, hvidbræmmet hovedklæde kastet over venstre skulder. Manden til venstre bærer - og er næsten skjult af - et stort, mørktindrammet maleri, der forestiller en jemenitisk velhaver i en koreansk bil med nummerpladen "Racer" foran en oase-scene, i hvilken en hyrde vogter får, og en bonde pløjer med en kamel forspændt arden. Øverst til højre i maleriet står bilmærket "Daewoo" - billedet viser os den traditionelle kilde til rigdom og dens synlige, essentielt europæiske symbol.

Den mand, der bærer maleriet, ser direkte ned mod kameraet, ud på betragteren, medens de to andres opmærksomhed er fanget af noget uden for billedet: de ser mod højre. Bag maleriet anes en bil af off-roader typen, og langs den er en mand i lys kjortel og mørk, europæisk jakke på vej frem i billedet; off-roaderens spejl reflekterer lyset og dækker hans venstre skulder. Helt i baggrunden et hus med et hvidtindrammet vindue.

Der er en række korrespondenser i billedet: mellem de hvide felter, fra porten til højre over den midterste mand til bilen på maleriet; og mellem det delvis skjulte hus bag muren og manden i mellemgrunden til venstre, sam-men med offroaderens sidespejl og baggrundshusets vindue. Der er også korrespondens mel- 
lem de mønstrede billeddele: porten til højre (hvori mønster og flade kontrasterer - og søjlernes gitter er blevet til et rhomboidt ekko af billede nr. 1), friserne på tårnet i mellemgrunden, maleriets ramme og den midterste mands traditionelle bælte med dolken, der er ligeså nødvendig for en korrekt klædt jemenit, som slipset er det for en ditto europæer - der er også her etableret en kobling mellem traditionelt og importeret statussymbol.

- Men allervæsentligst er korrespondensen mellem maleriets mørke ramme og den sorte ramme, fotografen har givet hele sit billede, hvorved en betydningsfuld relation etableres mellem den afbildede verdens billedbrug og fotografens egen billedproduktion. Det let ironiske, europæiske syn på den fremmede kulturs brug af vores symboler sættes i humoristisk relief: den europæiske fotograf eksotiserer det i grunden ueksotiske - og er det affotograferede maleri egentlig ikke et spejl, som den europæiske betragter har godt af at se sig selv i? 